\title{
Universidad, reforma universitaria y pluriversidad en el Perú
}

Recibido: 20/11/2017

Aprobado: 01/12/2017

\author{
Carolina Ortiz Fernández \\ Universidad Nacional Mayor de San Marcos \\ < cortizf@unmsm.edu.pe >
}

\section{RESUMEN}

Entendiendo que el saber es poder, en el presente trabajo se explora, desde la perspectiva sociohistórica y de género, cómo se ha ido organizando el saber en la estructura universitaria sanmarquina con un énfasis en las ciencias sociales. Asimismo, se explora de manera introductoria las propuestas de cambio. ¿¿Por qué se torna imprescindible pensar la universidad desde una perspectiva pluriversal, sociohistórica y de género, despatriarcal e intercultural descolonial? constituye una de las preguntas que se intenta responder.

PALABRAS CLAVE: Universidad, pluriversidad, reforma universitaria, género, interculturalidad descolonial, saber y poder

\section{University, university reform and pluriversity in Peru}

\begin{abstract}
Understanding that knowledge is power, in the present work I explore, from a sociohistorical and gender perspective, how knowledge has been organized in San Marcos University's structure with an emphasis on social sciences. Likewise, proposals for change are explored in an introductory manner. Why does it become essential to think about the university from a pluriversal, sociohistorical and gender perspective, depatriarchal and intercolonial perspective?
\end{abstract}

KEYWORDS: University, pluriversity, university reform, social-historical perspective, gender, descolonial intercultural, know and power

* El trabajo corresponde al proyecto de investigación (marzo 2016 / marzo 2017) a mi cargo: «Notas sobre la universidad y la pluriversidad en el Perú», presentado al Instituto de Investigaciones Histórico Sociales, Facultad de Ciencias Sociales, UNMSM. 


\section{Introducción}

E 23 de febrero de 2017, los medios informaban que los Apus, autoridades de los pueblos originarios, y representantes de las comunidades afrodescendientes y el Presidente del Poder Judicial, Dr. Duberlí Rodríguez se reunían por primera vez. El Palacio de Justicia que todo el tiempo ha sido renuente, abrió sus puertas. ¿Constituye esto un gesto oficial de apertura ante las demandas de los pueblos indígenas?

En la últimas décadas, las comunidades y pueblos de la Amazonia, vienen resistiendo con gran intensidad las políticas de recolonización y despojo de sus territorios y exigen que las decisiones tomadas en su jurisdicción se respeten, cuestionando así la imposición de las empresas petroleras y de monocultivos avaladas por las instituciones del Estado —que se arrogan la representación del «no saber-y del saber hegemónico impartido en las universidades, entre ellas, la ciencia económica y las ciencias sociales. Lo que nos conduce a preguntar. ¿Qué hacer desde las universidades?

De modo semejante, los movimientos de mujeres y feministas vienen planteando demandas que cuestionan el saber en todos los ámbitos. Estas demandas no pueden ser ignoradas por la universidad y menos por las ciencias sociales; existen esfuerzos individuales por propiciar una visión distinta, pero no son suficientes.

Una de las fuentes de la crisis de la universidad radica en su mirada y política monocultural y eurocénctrica, que se reproduce desde su creación al formar a los profesionales casi de manera exclusiva con anteojos euronorteamericanos. El no reconocer, por ejemplo, a la autoridad jurisdiccional de la comunidad Achuar, el no reconocimiento de sus prácticas culturales en los ámbitos de la economía, la agroecología, la jurisprudencia, entre otros aspectos, es una expresión de ello. La formación universitaria las ignora por considerarlas atrasadas e irrelevantes. Esta visión está tejida estrechamente con la dominación patriarcal y el racismo articulados por la economía mundo y la colonialidad del patrón global de poder. El orden social patriarcal impuesto en la mayor parte de sociedades con los procesos coloniales se ha afianzado de manera violenta y en las última décadas con mayor fuerza junto a las políticas de especulación financiera y los commoditties.

El orden social patriarcal y patrimonial moderno colonial entendido como la gestión y relación de autoridad, de organización social y del saber en procesos de larga duración globalizado por Occidente implica su organización desde la visión del hombre/ padre propietario, «blanco» y hoy en día impone sus normas y políticas en nombre del «estado nación» o «supranacional» y del mercado (sobre todo de las grandes corporaciones), presentándose de manera paternalista o autoritaria. La primera se esfuerza por inhibir la violencia que se ejerce cuando se piensa y considera que las mujeres no producen conocimiento, cuando se piensa que los pueblos son ajenos al saber, cuando se les cataloga de menores edad, mujeres y pueblos ignorantes que no saben pensar y que por eso necesitan ser tutelados por los profesionales que gobiernan; la legislación, la educación, la economía, lo avala. El segundo, implica el ejercicio autoritario de las relaciones y estructuras históricas de autoridad ejercido por las fuerzas del orden, el aparato jurídico, los medios de comunicación, el juez que se mofa y agrede, la universidad que programa estructuras curriculares ajenas a la realidad de más del 70\% de la población.

Esta relación de dominación patriarcal se teje con el racismo epistémico que niega las maneras de conocer y producir conocimiento de los pueblos no europeos por una supuesta naturaleza inferior, en ese sentido las instituciones de saber, entre ellas la universidad no permite que los estudiantes aprendan sin sentirse avergonzados de las prácticas culturales de su pueblo de origen, tampoco permiten introducir la visión de las mujeres en todas las áreas del saber. Los contenidos elaborados exclusivamente a partir de la visión masculina y patriarcal predominan en las estructuras curriculares. La ausencia de la producción y reflexión intelectual y de referencias bibliográficas de mujeres en los sílabos es notable en pleno siglo xxI. Situación que se agrava cuando hacen uso de los aportes de las mujeres silenciando su procedencia, lo que constituye un signo de decadencia y extractivismo intelectual.

A esto se suman los desastres naturales y el calentamiento global que se acrecienta por el modelo extractivista, los relaves mineros, la deforestación, la contaminación industrial, entre otras prácticas ecocidas. En las diversas disciplinas se encuentra muy arraigada la visión de concebir a la Naturaleza como un objeto inerte, un simple objeto de explotación, un objeto sin vida ajeno a la especie humana, avalando de este modo las políticas de desarrollo que conducen a su destrucción.

Ergo, no es posible señalar que la enseñanza es neutra y apolítica. El saber es poder y está vinculado históricamente a las relaciones de control del territorio, 
de los bienes comunes, de la subjetividad, el trabajo, la relación sexo-género, la autoridad.

La Ley Universitaria 30220 y el Modelo Educativo San Marcos vigente no son ajenos a lo planteado. Ambos proyectan la modernización de la Universidad pero sujeta a los requerimientos de la Organización Mundial del Comercio, del patrón global de poder que busca la sujeción de las universidades a las necesidades de las financieras y corporaciones transnacionales.

La crisis de la Universidad en América del Sur ha sido planteada en los últimos años por varios autores. Para Boaventura de Sousa Santos (2005) la universidad atraviesa por tres crisis, la primera, una crisis de hegemonía debido la contradicción entre los factores funcionales tradicionales y los atribuidos en el siglo Xx y XxI, vinculados al fomento de la concentración e incremento sin fin de capital.

La segunda, crisis de legitimidad, debido a la contradicción entre la jerarquización de los saberes especializados y las exigencias sociales y políticas de democratización y reivindicación de los hijos de las clases populares. Y la tercera, crisis institucional por la contradicción entre la presión de alta productividad con visión empresarial y la necesidad de autonomía que los movimientos sociales demandan en los últimos años. En suma, la universidad ha dejado de ser un bien público en sentido estricto, en tanto el estado redujo su responsabilidad con la educación general y en particular con la universidad.

Freire (2011 [1993]) y un conjunto de intelectuales pertenecientes a la teoría crítica transformativa, con influencia marxista, critican la educación funcionalista hegemónica que reproduce el status quo y apuestan por una educación comprometida con las maneras de aprender subalternizadas e impulsan la formación de intelectuales transformativos.

César Germaná, en una exposición sobre la reforma universitaria sostuvo que desde sus orígenes la universidad ha sido colonial porque formó a los responsables que se encargaron de imponer una perspectiva de conocer que inferioriza a los dominados. ${ }^{1}$

Edgardo Lander (2015) precisa que, además de la conminación externa a nivel global sobre la vida universitaria, las amenazas internas constituyen un gran riesgo; la sujeción al desarrollismo, el individualismo y el consumismo configuran el diseño de las estructuras

1 Exposición realizada en la Universidad Ricardo Palma el 2014 que fue comentada por quien escribe este texto. curriculares. Las exigencias de evaluación y acreditación, tal como se vienen imponiendo, crean un clima de subordinación a las exigencias de las corporaciones educativas y al cortoplacismo, en tanto hace que se viva gestionando las urgencias.

Por todos estos motivos, apremia crear espacios públicos de pensamiento crítico que interpele la sujeción a las exigencias del Banco Mundial, la OMC, del capital transnacional educativo. Por eso, además de lo planteado por estos autores, considero que ante los movimientos sociales y epistémicos de las mujeres, de los movimientos populares de las comunidades y pueblos afroindígenas que se afianzan en los últimos ańos y que no podemos ignorar, es imprescindible establecer diálogos con ellos, abrirse a lo que se suele considerar el «no saber».

Es pertinente señalar que pareciera que en los últimos años, el Estado se interesara en atender las demandas de los movimientos sociales, lo vemos a través de sus planteamientos en la nueva política educativa y el currículo nacional, la reciente introducción de la perspectiva de género, que ha producido iracundas reacciones, y una pequeña ampliación de la educación intercultural bilingüe, su gran limitación es que permanece la visión hegemónica empresarial que defiende el modelo económico extractivista promovido por el mercado de servicios universitarios a nivel nacional, ahora transnacionalizado; la política educativa sigue constreñida a esos parámetros.

\section{La universidad y los procesos coloniales}

$\mathrm{Si}$ bien las universidades latinoamericanas fueron fundadas en el siglo XVI, la UNMSM en 1551, la Universidad de México en 1553, de Santo Domingo en 1530, nuestra historia en relación al conocimiento no comienza allí, los pueblos originarios, como lo señala Enrique Dussel (2013), tuvieron «instituciones por medio de las cuales las generaciones responsables de la gestión de la sociedad prepararon a las nuevas generaciones para que pudieran reemplazarlos en su momento correspondiente.» Siguiendo a Bernardino de Sahagún precisa que había más de 300 profesiones en la cultura azteca. En el Calmecac se formaban a las nuevas generaciones nahuas, igualmente ocurrió en la civilización Inca y pre Inca.

Felipe Guaman Poma precisa en la Nueva corónica y buen gobierno (1993 [1615]) que en la sociedad 
Inca la formación de las nuevas generaciones estaba a cargo de las mujeres y los hombres mayores. Se encargaban de transmitir en la cotidianidad de la vida, el conjunto de conocimiento según la edad, la diferencia sexual y la visión sagrada de la vida. Se les formaba en agroecología, arte textil, ganadería, caza, música, danza, religiosidad $\mathrm{Y}$, astronomía, arquitectura, ingeniería hidráulica, medicina, minería. A los 15 años empezaba el entrenamiento militar.

Los antiguos maestros se llamaban camascaamautaruna, quienes entendían el lenguaje de las estrellas, los cometas, los eclipses, las "tempestades de aire», de los animales y pájaros. Los camascaamautaruna eran expertos en leer y comprender los signos vitales de toda la naturaleza y a través de esa lectura podían predecir el devenir.

Todo esto cambió desde el siglo xvI. Las universidades creadas en esta región fueron un instrumento e institución funcional a las políticas coloniales; propiciaron el proceso de evangelización y la extirpación de idolatrías, por cuanto las teorías que difundieron contribuyeron al etnocidio y epistemicidio de los pueblos y a la apropiación y explotación de sus territorios. desatar

En la Universidad de San Marcos la enseñanza de la jurisprudencia, la teología y la medicina estuvo asociada a ese proceso, en tanto constituyeron los tres pilares del orden social. La medicina se ocupó de las tecnologías sobre el cuerpo, la teología de los imaginarios y la jurisprudencia de las reglas de la organización social sujetas a los requerimientos de la corona y de las élites coloniales. Más, como todo campo de acción, la universidad supuso y supone fuerzas en movimiento.

Si el pensamiento y la estética modernos se configuran a partir de un lugar geohistórico y político de enunciación, ambos tuvieron como punto de partida el violento encuentro entre los íberos y los pueblos indígenas del sur de este continente en el siglo xv. Enrique Dussel (2001) y Quijano sostienen que la modernidad surgió gracias a América (1988). Por un lado, abrió posibilidades liberadoras en toda relación social, institucional, estructural $y$, al mismo tiempo, nuevas formas de explotación y dominación a través de los procesos y políticas coloniales que expandió la hegemonía del eurocentrismo, la idea de raza en toda relación social (Quijano, 1991), y el afianzamiento de la dominación patriarcal. Sin embargo ocurrido el violento encuentro, el pensamiento crítico, el pensamiento otro, no se hizo esperar. Se halla en la
Nueva corónica y buen gobierno, de Felipe Guaman Poma; en los Comentarios reales del Inca Garcilaso de la Vega, en la danza, en la música, en la pintura de la Escuela Cusqueña y Quiteña.

En el episteme impuesto, la ciencia, que implica un esfuerzo por sistematizar el conocimiento secularizado, se asoció a Occidente y a la racionalidad de los varones. Todo saber producido por la civilización inca y pre inca fue considerado una simple creencia irrelevante de pueblos primitivos no viriles. ${ }^{2}$

El objetivo de la ciencia desde la visión europea radica en perfeccionar el conocimiento de la naturaleza para su mejor explotación. Durkheim, Niesztche y Wallerstein nos recuerdan que la ciencia se fue alejando de valores como la generosidad, la belleza, el amor porque las ciencias denominadas exactas fueron separadas de los denominados saberes especulativos; en su lugar advino la categoría progreso que adquirió un sentido de linealidad e infinitud. Separó al cuerpo de la razón, a la naturaleza de la cultura. Las universidades sudamericanas siguieron y afianzaron estos lineamientos del saber y junto a la iglesia potenciaron la dominación y organización sociosimbólico patriarcal, la explotación de la naturaleza, la racialización de las relaciones sociales que se enraizó en todas las instituciones.

El orden sociosimbólico patriarcal, fortalecido por la relación colonial de Occidente, asociado a la diferencia sexual y a la propiedad privada y acumulación originaria de capital implica la centralidad y concentración de poder y saber en defensa de las propiedades y privilegios de los grupos de poder, conformados eminentemente por varones. Sus primeros arraigos se asientan en la estructuración histórica de la vida doméstica, el control de la sexualidad, el cuerpo y el trabajo de las mujeres, el control del trabajo y el cuerpo de los trabajadores, en la estructura jerárquica de la iglesia y el ejército, y se fue expandiendo al mundo público, a las instituciones de gobierno y la sociedad en procesos de larga duración, hasta afincarse históricamente en toda relación social, tanto en lo micro y macro social. Los procesos coloniales afianzaron esta relación del poder en la construcción histórica de las estructuras del saber desde la visión del sujeto masculino, occidental, propietario, blanco, letrado, cristiano, "civilizado» que asume la representación del «no saber». Desde esta

2 El sentido de pueblos viriles y no viriles se formula en el Tratado sobre las justas causas de la guerra contra los indios, Juan Ginés de Sepúlveda; México, FCE., 1996 [1550]. Recuérdese que Sepúlveda fue preceptor de los príncipes. 
visión se organizó cada una de las disciplinas de las ciencias clasificadas como nomotéticas e ideográficas.

En 1855, en la Universidad Nacional Mayor de San Marcos, los colegios mayores pasaron a ser facultades y al igual que en Europa unos años más tarde se clasificó en ciencias y letras, división que constituyó en occidente la demarcación de las dos culturas referidas por Snow, ${ }^{3}$ y que los procesos coloniales requerían para ampliar y no perder su dominio sobre los territorios que se habían independizado políticamente. Vale recordar que en 1959, Charles Percy Snow (19051980) en una conferencia realizada en Cambridge con el título de "Las dos culturas y la revolución científica", muy comentada y polémica en su tiempo, cuestionó el cisma ocurrido en el mundo académico de occidente entre científicos/ingenieros y los artistas/literatos, por ser sumamente nocivo. Los «científicos» dice: "prestan escasa atención a la cultura humanista e incluso la miran con desdén» (Snow, 1959) y los artistas/ literatos muestran un escaso interés y un profundo desconocimiento de los avances científicos, de la Revolución Científica e Industrial que tuvo lugar desde fines del siglo XIX. Esta división llena de prejuicios e incentivada por los grupos de poder económico y la dominación patriarcal con el objeto de asegurar el poder económico del hombre/padre propietario que se arrogó la autoridad de organizar el saber, produjo un gran cisma en la vida académica con una repercusión negativa en el individuo y la comunidad.

La Facultad de Ciencias en San Marcos fue asociada a la capacidad de medir y calcular por lo que fue llamada cuna de las ciencias exactas capaces de conducir al supuesto "progreso indefinido", mientras que las letras o humanidades fueron asociadas a la ética y a la estética que desde esa visión hegemónica serian en estricto especulativas. La Facultad de Ciencias fue dividida en tres secciones: ciencias matemáticas, ciencias físicas y ciencias naturales.

\section{El primer proyecto moderno colonial en la Universidad}

En 1876, a iniciativa de José Antonio Barrenechea y al proyecto moderno liberal de Pardo se creó la Facultad de Ciencias Políticas y Administrativas. Para disminuir la especulación en la Facultad de Letras, siguiendo a Comte, que acuñó el concepto de física social, se

3 Citado por Wallerstein en Abrir las ciencias sociales. creó la cátedra de sociología en 1896, a sugerencia de Mariano Hilario Cornejo, del presidente Piérola y del rector García Calderón. Se pensó que la sociología era una ciencia exacta. Este constituye el primer proyecto moderno colonial de secularización de la universidad antes de la reforma de Córdova por su espíritu desacralizador y laico.

Mariano Hilario Cornejo, diplomático y parlamentario, tuvo una formación erudita y un conocimiento vasto del pensamiento europeo e introdujo la mirada laica en el gobierno y en el proceso de conocer y comprender la vida social. Esto fue notable. Con todo, a pesar de haber vivido en Puno durante su etapa escolar en la que tuvo a profesores alemanes, a su formación en filosofía y letras; en sus propuestas y obras ignoró e invisibilizó a la mayoría de la población peruana: la población indígena y las mujeres, un $90 \%$ de la población.

El plan de estudios de aquellos años comprendía las siguientes materias: Filosofía Antigua y Moderna, Estética, Literatura Castellana, Antigua y Moderna; Historia de la Civilización, Historia de la Civilización Romana, Sociología y Pedagogía. Al revisar este material en el Archivo Histórico Domingo Angulo de nuestra universidad, pude apreciar que la creación de nuevos cursos mantuvo los contenidos dedicados a espacios y experiencias exclusivamente de Europa occidental. A través del darwinismo social, se afianzó la supuesta naturaleza inferior de los pueblos de la región sudamericana, fueron considerados ágrafos, bárbaros, carentes de historia, de filosofía, no eran plenamente humanos.

En ese proceso, la visión de las mujeres fue muy distinta. Trinidad Enríquez Ladrón de Guevara, Laura Esther Rodríguez y Esther Festini lograron conquistar, después de un largo proceso, su ingreso a la universidad, la primera ingresó a la Universidad San Antonio de Abad de Cusco, en 1875; la segunda, conquistó su ingreso a la Facultad de Ciencias Matemáticas Físicas y Naturales de la Universidad Nacional Mayor de San Marcos en 1894, fue la primera mujer que juramentó como médica cirujana el 25 de octubre de 1900 (Ortiz; 2008). Trinidad Enríquez reconociendo el saber de los artesanos cusqueños, de manera autónoma, fundó la primera Escuela de Artesanos en Cusco.

Esther Festini fue la primera mujer que en 1901 obtuvo el grado de bachiller en la Facultad de Letras de la Universidad Nacional Mayor de San Marcos con la tesis: «El rol que corresponde a la mujer en la sociedad 
es el que determina su educación» (Ortiz, 2008) cuya publicación en los Anales Universitarios fue aprobado por el jurado. En 1904, continuando con su interés por la educación de las mujeres, sustentó la tesis "Cuestiones relativas a la educación femenina», con la que obtuvo el grado de doctora en Letras.

Las propuestas de la teoría social funcionalista difundidas por el curso de sociología inaugurado por Cornejo, le permitió comprender que las identidades de género son construidas socialmente y no por determinación divina, pero completamente aisladas de las relaciones históricas de dominación y explotación sujetas a la clasificación socioeconómica, etnoracializada y de la organización sociosimbólica patriarcal. En cambio, fuera de la vida universitaria, ajenas al funcionalismo y con una mirada mas integral, Mercedes Cabello de Carbonera logró comprender la asociación entre la construcción social de las identidades genéricas con las relaciones socioeconómicas, la dominación patriarcal en la intimidad y en la vida pública. Indagó y reflexionó sobre la construcción social de los caudillos, tan usual y patriarcal en América Latina. Por otro lado, Clorinda Matto de Turner asoció las relaciones de dominio y explotación etnoracializadas con las relaciones de dominio y explotación del trabajo y el cuerpo de las mujeres (Ortiz, 1993). ¿Por qué la universidad no logró comprender estas relaciones de dominación a fines del siglo XIX? ¿Se encontró imbuida exclusivamente de la mirada omnipresente masculina, de racismo y eurocentrismo? ¿Ha cambiado esto hoy?

\section{La Universidad en el siglo XX}

En los años veinte del siglo xx, la universidad como institución continuó siendo una estructura académico administrativa vertical, autoritaria y elitista, que excluía a la mayoría de la población peruana de su derecho a la educación: las mujeres, los sectores populares y los pueblos originarios. El programa de la Reforma Universitaria, promovido en la ciudad de CórdovaArgentina, fue defendido en Uruguay, Chile, Perú; los estudiantes reivindicaron la democratización de la Universidad Peruana, pero siempre con el espejismo de la dominación patriarcal, el eurocentrismo y su colonialidad. Por eso, es destacable la precisión de Mariátegui cuando expresa que «En el Perú, por varias razones, el espíritu de la Colonia ha tenido su hogar en la Universidad. La primera razón es la prolongación o supervivencia, bajo la República, del dominio de la vieja aristocracia colonial.» (1995 [1928]: 99) pero no como herencia colonial sino como un vestigio que se subordina a las relaciones establecidas por el patrón global de poder del siglo xx y su colonialidad.

\section{Peruanicemos el Perú}

Esta frase de José Carlos Mariátegui proviene de Andrés Avelino Cáceres. Clorinda Matto de Turner lo menciona y hace suya. En el periódico Los Andes, fundado por Cáceres, se encuentran algunas referencias que vinculan el sentido de peruanizar el país, en el contexto de la guerra del Pacífico, con la defensa de las prácticas culturales propias, por ejemplo la defensa de la «lengua madre»: el quechua y la defensa del territorio; dado que sus elites pensaban y actuaban en función a intereses foráneos. El sentido de «peruanizar el Perú» se afirmó en las primeras décadas del siglo xx con Mariátegui y los indigenistas. En la universidad, a iniciativa de José de la Riva Agüero se propuso el curso de Historia del Perú aunque construido desde la perspectiva histórica masculina y europea.

En los años 60, ante los movimientos campesinos a lo largo del país que antecedieron a la reforma agraria, y el creciente proceso de urbanización, los nuevos migrantes conquistaron su ingreso a la vida universitaria. En el área de las ciencias sociales fue una época crucial de debate en torno a la postura estructural funcionalista y la mirada histórico estructural.

El régimen militar que se inició en 1968, mediante el Decreto Ley 17437, Ley de la Universidad Peruana de 1969, formuló un modelo de modernización que se propuso organizar el «Sistema de la Universidad Peruana» basado en la conformación de Consejos Ejecutivos y en la Departamentalización Académica que limitaba la participación estudiantil y de docentes en el gobierno de la Universidad persistiendo así la centralidad de la autoridad, uno de los ejes de la dominación patriarcal e imponiendo de esta manera una concepción tecnocrática y despolitizada en la vida universitaria. Los contenidos de los planes de estudio continuaron siendo la repetición y aplicación de las perspectivas euronortreamericanas aunque con un despliegue de la mirada propia a partir teoría de la dependencia.

Las dictaduras militares de los años 70 en América Latina centralizaron y concentraron el poder también en la vida universitaria. 
En los 90, durante la funesta década del fujimorismo, la política neoliberal del régimen sujeta a las demandas del patrón global de poder, violó la autonomía universitaria al intervenir militarmente varias universidades públicas tanto al interior de la provincia de Lima como en otras universidades del país. El orden sociosimbólico patriarcal en su versión totalitaria estrechamente vinculada al neoliberalismo controló la administración, las actividades académicas y la producción intelectual en la vida académica, poniendo en marcha un proceso que empezó a eliminar la "gratuidad» de la enseńanza y a afianzar la concepción de universidad como si fuese una autoritaria corporación empresarial, contribuyendo a educar los sentidos, a modelar los cuerpos y los modos de ver según los requerimientos simbólicos hegemónicos y geopolíticos del mercado mundial y de las elites «nacionales» dependientes de ese poder, hasta convertir al estudiante en cliente y al docente universitario en un trabajador por horas, con las características del trabajo a destajo, con numerosos alumnos, que le impide desempeñar adecuadamente su labor académica y de investigación; los profesionales que egresan se convierten en «técnicos» o «tecnócratas» de los organismos públicos y privados. Desde entonces, se ha ido perdiendo la visión crítica.

La formación en todas las disciplinas incluida las ciencias sociales, desde la perspectiva estructural funcionalista y el marxismo eurocéntrico, con algunas variantes contemporáneas, se han ocupado de legitimar las políticas de desarrollo, con una visión lineal de progreso indefinido hoy vinculado al extractivismo, impartiendo cursos de demografía y desarrollo, sociología del desarrollo, economía del desarrollo, antropología del desarrollo, como parte de un saber poder global eurocentrado que ocasiona el despojo y la destrucción de la Naturaleza.

Las estrategias de desarrollo extractivistas constituyen la base de formación de los políticos y técnicos profesionales que gobiernan el país. Estas se expresan, desde Bacon, en la cosmovisión de la ciencia y tecnología de la tradición eurocéntrica, que promueve la explotación sin fin de la Naturaleza poniendo en riesgo la vida del planeta. Por eso, las catástrofes no son siempre naturales, son motivadas por esta política de sobreexplotación de los bienes comunes avalada por el saber hegemónico en la universidad que no contribuye a resolver los problemas sino a agravarlos.
El modelo económico actual y su aparato educativo a través de la nueva ley de educación y la ley universitaria abre algunos espacios para la mirada intercultural, promueve becas y la participación de los denominados grupos de interés, pero los gestos (neocoloniales para unos ) o mejor la colonialidad del poder se mantienen, por cuanto la Universidad pierde cada vez mas autonomía por la injerencia de las corporaciones, se pretende educar teniendo como mira los yacimientos mineros, sin importar la gravedad de la crisis ecológica, entonces se presiona para que el mundo académico se subordine a ellos. Además, como bien lo expresa Lander, toda la normatividad en torno a la evaluación docente, a la acreditación y a los parámetros de publicación continúa siguiendo el modelo norteamericano.

Con todo, los movimientos sociales, epistémicos y estéticos de las mujeres, de los pueblos afroindígenas, las culturas populares, las comunidades LGTBIQ se encuentran resistiendo, cuestionando el saber y proponiendo alternativas para afrontar los problemas mundiales.

\section{Reforma universitaria en el sigloXXI, pluriversidad y descolonialidad del poder}

\section{Provincializar Europa para la pluriversidad}

Comprendiendo que el creciente poder del capital financiero y el patrón global de poder se mueve entre crisis, sobre todo la crisis ecológica que pone en riesgo la vida del planeta, en tanto existe una creciente concentración del poder político y económico que se sustenta en el control del conocimiento y la subjetividad que fortalece el control del trabajo, de los bienes comunes, de la economía del cuidado y de las relaciones sexo/género de la mayor parte del planeta-; ya no es posible continuar con la estructura universitaria actual. La nueva Ley universitaria 30220 supone solo su modernización.

La crisis generalizada hace indispensable mutar la vida en general y la vida universitaria en particular, propiciando una educación pública pluralista, pluriversal en términos de Boaventura de Sousa (2005), multiversidad en términos de Edgar Morin (1999) vinculada a la problemática del mundo social y la gratuidad de la enseńanza, con una comunidad universitaria plural, agrego, intercultural, democrática 
y descolonial orientada a las necesidades de los pueblos y de la población.

Es importante tener presente que el movimiento por la educación de los jóvenes en Chile como bien lo menciona C. Walsh (2015) demanda una educación no humanista porque la visión humanista está caduca, en tanto ha gestionado la destrucción del planeta, la destrucción epistémica y territorial de los pueblos. Humanismo y capitalismo se asocian por cuanto el proyecto moderno del patrón global de poder supone «humanizar» a los bárbaros.

La universidad otra será pluralista o pluriversal si se provincializa Europa. Esta propuesta se inspira en Arguedas, (Ortiz, 2004) supone el descentramiento y desprendimiento del sujeto europeo que se impuso a nivel mundial en el conocimiento a través de los procesos coloniales, de este modo se fractura la totalidad autoritaria unívoca, lineal y uniforme del eurocentrismo. La universidad otra no puede ceñirse de modo fundamentalista a una sola corriente sino que deberá poner en concierto y debate las pluralidad de perspectivas.

En El Zorro de arriba y el Zorro de abajo, en la polémica con Cortázar entre otros acontecimientos, podemos encontrar que para Arguedas no existe el saber si no lo saberes, si esto es así todo saber es provinciano, el europeo es uno más entre muchos, pero es el que se ha impuesto como el único válido y por lo tanto superior.

Provincializar Europa no significa negar sus aportes, sino que desconcentra su poder. Implica cuestionar al sujeto teórico europeo que se ha erigido como soberano en los discursos científicos con el apoyo de las élites del Perú y América Latina a través de la construcción disciplinaria del saber que defiende la continuidad y la racionalidad del neoliberalismo con una visión fundamentalista del mercado. Provincializar Europa implica la descolonialidad del saber, la descolonialidad de las ciencias, en particular de las ciencias sociales, (Ortiz, 2004) supone develar el episteme colonial y ecocida, revelar las construcciones burocráticas de ciudadanía del Estado nación.

El episteme/ cosmovisión hegemónico impuesto mediante la fragmentación disciplinaria en ciencias sociales y humanidades, el occidentalismo, el racismo y la dominación masculina y patriarcal en el conocimiento, impiden acercarnos en mejores condiciones al entendimiento de la complejidad de lo real, a las relaciones socioeconómicas y a la dimensión simbólica que lo componen; con todo, existen numerosos esfuerzos por establecer nuevas perspectivas desde visiones díalógicas, de género e interculturales descoloniales. Esto supone el desprendimiento o ruptura epistémica del marco de saber y poder que se impuso con los procesos coloniales y persisten en el mundo de los afectos, el trabajo y el territorio. Este episteme y estética otras emergen de las situaciones y existencias de dolor y sufrimiento de los oprimidos, de la energía que renace en la resistencia y supervivencia cotidiana, en los espacios libres de los sueños y la música, en el desarraigo, en las perspectivas, saberes y reflexiones otros que provienen de los los cuerpos y saberes que resisten, subvierten e irrumpen en el mundo, sobre todo en Meso y Sudamérica.

Provincializar Europa y sentipensar la pluriversidad, desde la visión descolonial significa contribuir a formar una genealogía epistémica distinta a los parámetros occidentales impuestos como lo planteó José María Arguedas en su famoso discurso "No soy un a aculturado», al recibir el premio Inca Garcilaso de La Vega en 1968 desde la visión de un «quechua moderno».

Arguedas recibió con alegría el premio Inca Garcilaso de la Vega, porque sintió el reconocimiento a la labor de "difundir y contagiar en el espíritu de los lectores el arte de un individuo quechua moderno que, gracias a la conciencia que tenía del valor de su cultura, pudo ampliarla y enriquecerla» (1978) con el conocimiento, la recreación o asimilación resemantizada de los saberes creados por otros pueblos pero sin la repetición e imitación colonial. La genealogía arguediana tiene como punto de partida el reconocimiento de la heterogeneidad territorial y humana del país, veamos:

No, no hay país más diverso, más múltiple en variedad terrena y humana, todos los grados de calor y color, de amor y odio, de timbres y sutilezas, de símbolos útilizados e inspiradores. No por gusto, como diría la gente llamada común, se formaron aquí Pachacámac y Pachacútec, Huamán Poma, Cieza y el Inca Garcilaso, Tupac Amaru y Vallejo, Mariátegui y Eguren, la fiesta de Qoyllur riti y la del señor de los Milagros; los yungas desde la costa y de la sierra; la agricultura a 4000 metros; patos que hablan en lagos de altura donde todos los insectos de Europa se ahogarían; picaflores que llegan hasta el sol para devolverle su fuego y llamear sobre las flores del mundo. Imitar desde aquí a alguien resulta algo escandaloso. (Arguedas 1978: 3) 
La genealogía propuesta por Arguedas es mucho más democrática, establece puentes entre mito y razón cuestionando la instrumentalización de la razón, pero continúa siendo evidentemente masculina y patriarcal.

Si consideramos el episteme, siguiendo a Foucault, como el marco de interpretación, de valoración y de saber según el régimen de verdad asignados por los dispositivos y relaciones de poder en distintas épocas en procesos de larga duración, por eso sería casi imposible concebir las cosas y las palabras desde otro marco, la resistencia epistémica implicaría establecer una ruptura o desprendimiento de ese marco, o mejor de esta cosmovisión. En ese sentido, Quijano, por su parte, explica los dilemas de ese desprendimiento en tanto no basta la negación simple de todas sus categorías, «es necesario desprenderse de las vinculaciones de la racionalidad-modernidad con la colonialidad, en primer término, y en definitiva con todo poder no constituido en la decisión libre de las gentes libres. Es la instrumentalización de la razón por el poder colonial, en primer lugar lo que produjo paradigmas distorsionados de conocimiento y malogró las promesas liberadoras de la modernidad. (Citado por Mignolo, 2012)

Lo que le falta a Foucault es la ubicación geohistórica de los procesos coloniales modernos y el patrón global de poder que sí es percibido desde América Latina y África. En el marco de saber hegemónico, las teorías del desarrollo formuladas por las disciplinas y sus expertos formados en las universidades a partir de la razón instrumental, defienden la desregulación del mercado, propician la concesión/ ocupación de territorios afroindolatinoamericanos y africanos para la explotación indiscriminada de la naturaleza y son responsables del desastre ecológico que pone en riesgo la vida misma del planeta.

El conocimiento, la ciencia y la tecnología, no está al servicio de los pueblos sino de las grandes corporaciones. La geopolítica epistémica se reconfigura y moderniza estableciendo el extractivismo epistémico. Por eso, se trata de dialogar, aprender y revalorar los conocimientos ancestrales, pero, en acuerdo con C. Walsh, sin que el Estado ni las corporaciones asuman el control de ellos, sino que se construya una gestión del conocimiento mediante lo que Walsh (2015) denomina economía social de conocimiento.

Para las organizaciones de las mujeres y hombres indígenas, los cuerpos de las mujeres, los pueblos y los territorios invadidos tienen algo en común, son violentados y despojados por el estadoy las corporaciones con el fin de extraer y consumir toda su energía. Por eso, la pluriversidad supone la descolonialidad epistémica, lo cual implica provincializar Europa y los Estados Unidos, desracializar, despatriarcalzar el ser y el saber, abrirse y escuchar al «no saber» (Ortiz, 2004) transgredir las fronteras disciplinarias que impiden tener una visión integral, supone la ruptura constante con la relación colonial entre sujeto y objeto de conocimiento, recuperar y recrear los saberes subalternizados, revalorar y propiciar la economía del cuidado en toda relación social, por cuanto tiene como principio y fin la relación afectuosa y armónica con la Naturaleza, con sí mismo, con la prójima y el prójimo, además de formar una genealogía epistémica distinta.

\section{Disciplinariedad y transdisciplinariedad}

La universidad construida desde la clasificación disciplinaria aisladas unas de otras no permite comprender la complejidad de lo real, la mirada disciplinaria enceguece, establece parcelas, aísla, disciplina los cuerpos para que no aprendan a ver con amplitud, "conduce a la ligereza cuando lo real es complejo», como bien señaló Cesar Germaná en una exposición suya. ${ }^{4}$

Desde la visión disciplinaria, caracterizada por llevar anteojeras, se podría señalar que el muchacho que disparó en febrero de este año en el centro comercial de Independencia es un psicópata y nada más y que por eso, la solución para evitar estos sucesos, es puramente punitiva o de atención psicológica. Según las estadísticas, los centros de salud registran un creciente número de jóvenes con ese diagnóstico, por lo que es pertinente preguntar si ¿son los problemas de salud mental, un problema estrictamente individual y familiar, aislado de la crisis que atraviesa la sociedad peruana y el planeta? La disciplinariedad, por su carácter particularista, enfoca el problema sin una mirada integral, invisibiliza el carácter multidimensional de los grandes problemas humanos y sociales.

Los estudios culturales, desde los años 80, la visión de Edgar Morin (1999) y Wallerstein (1997) coinciden al señalar que el conocimiento especializado extrae al objeto del conjunto, no tiene en cuenta las interdependencias. Morin manifiesta que:

4 Exposición realizada en la Universidad Ricardo Palma el 2014. 
La economía, por ejemplo, que es la ciencia social matemáticamente más avanzada, es la ciencia social y humanamente mas atrasada puesto que se ha abstraído de las condiciones sociales, históricas, políticas, psicológicas, ecológicas inseparables de toda actividad económica. Por eso sus expertos son cada vez más incapaces de interpretar las causas y consecuencias de las perturbaciones monetarias y bursátiles, de prever y predecir el curso económico incluso a corto plazo. El error económico se convierte, entonces. En la primera consecuencia de la ciencia económica. (Morin, 1999: 19)

Cuando lo complejo es parcelado no se logra ver lo multidimensional. Siendo el ser humano de carácter biosocial, psique, sociedad y cultura, una totalidad compleja, se ha desmembrado en compartimentos separados unos de otros haciendo imposible su comprensión.

Así, el mundo de los afectos, de las emociones, la poesía, la subjetividad se encuentran en las facultades de letras y humanidades cuasi divorciadas de las ciencias sociales; mientras que la dimensión económica, las ingenierías, la biología, la medicina, se encuentran enclaustradas en la facultad de ciencias nomotéticas.

Es imperioso reencontrar el principio de totalidad, entendiendo que este es plural. Un todo interconectado atravesado de relaciones sociales de confrontación, interdependencia y seducción por la colonialidad del poder. Para esto, se requiere conocer la acción performática de las instituciones hegemónicas, sus políticas de reapropiación de lo nuevo, el geoextractivismo epistémico que se expresa en sus políticas represivas o de seducción a nivel local y planetario. Implica propiciar perspectivas transdisciplinarias y dialógicas.

Lo mejor de nuestra tradición peruana y latinoamericana, Guamán Poma, Clorinda Matto, Mercedes Cabello, Vallejo, González Prada, Mariátegui, Arguedas, Quijano, Flores Galindo, los hermanos Santa Cruz, entre muchos y muchas más, estuvo alejada o agrietó la estructura disciplinaria, porque entendió que es imposible comprender los problemas humanos y sociales sin tener en cuenta la complejidad de lo real,

Es necesario recordar que el esfuerzo por dar la palabra a otras culturas, convirtió al estructuralismo en los ańos 60 en la postura teórica de izquierda, pero como sabemos este proceso se dio desde la versión positivista de la pretendida posición neutral del observador y de la relación colonial entre sujeto y objeto de conocimiento. Hoy en día, los diversos grupos sociales y culturas, los movimientos sociales y epistémicos de las mujeres, los pueblos afroindígenas, las comunidades LGTBIQ toman la palabra en la escena pública, erosionando la relación colonial entre sujeto y objeto de conocimiento que la universidad otra, la pluriversidad tiene el compromiso de asumir.

La mirada integral transgrede y trasciende las fronteras disciplinarias, alude a múltiples raíces y universos en incesante mutación y, al mismo tiempo, infinitas posibilidades. $\mathrm{Si}$, como se sabe, pero se olvida, todo está en constante movimiento, en un continuo siendo, es perentorio reconocer la provisionalidad del saber; los docentes y estudiantes tienen que estar preparados para construir y deconstruir, para aprender y desaprender, y en ese sentido considerar la incertidumbre como parte del proceso de conocimiento

\section{Escuchar la voz de nuestros origenes}

Si se entiende que el aprendizaje y la investigación es una colabor, que todo conocimiento es inacabado e incompleto, y que por eso es indispensable propiciar la perspectiva dialógica e intercultural descolonial con el «no saber», se empezará aprendiendo a escuchar la voz de los orígenes, en tanto hijos e hijas de la tierra, el agua, el fuego, el cosmos y los afectos, la composición humana los contiene. Siendo el ser humano cosmos, sociedad, psique, cultura, apremia recuperar y recrear los saberes y sentires ancestrales recluidos en el mundo interior. El conocimiento que se produce desde estas perspectivas fortalece la autonomía individual y las relaciones comunitarias.

Este proceso emancipatorio descolonial desde el cuerpo y la psique se configura cuando los sujetos sociales considerados "objetos» de investigación se apropian de su propia voz, cuando se contraviene la herida colonial, racista y patriarcal. Este carácter de la resiliencia se expresa mediante actos comunicativos que no solo cuestionan e interpelan sino que plantean propuestas creativas ante toda relación de dominio, en particular ante la relación colonial entre la autorizada voz del investigador cuyo ego racializado, sexista y clasista se impone sobre el «no saber».

La descolonialidad del conocimiento, por tanto de la universidad, requiere del enjuiciamiento crítico y descolonial de las ciencias, la crítica a sus fundamentos teóricos y metodológicos. 


\section{Despatriarcalizar el saber}

Lo que conocemos como ciencia moderna universalizado por el eurocentrismo, como bien lo expresa la física y filósofa Vandana Shiva (1999) es un paradigma reduccionista y mecánico de la proyección específica del hombre occidental que las élites latinoamericanas blancas y letradas imitaron, agrego, y en tanto proyección masculina y patriarcal no significó una fuerza liberadora para toda la humanidad sino que implicó el control de la Naturaleza, la Pachamama en términos quechuas, de las mujeres y los pueblos no europeos.

Las perspectivas de las mujeres provenientes de los sectores populares, de los pensamientos del afuera o de las fronteras disciplinarias ingresaron a la academia, en el caso sanmarquino, en los años 90 y con mayor fuerza en el siglo XXI; ellas además de considerar las clasificaciones socioeconómicas en sus investigaciones empezaron a cuestionar la relación colonial y racializada del sujeto masculino y femenino «blanco/a» «ablancado», «criollo» sobre el «objeto femenino», «chola», «indígena», «negra», «mestiza», LGTBIQ, que fundamenta las perspectivas teórico patriarcales de las fuentes disciplinarias.

Para esto fue necesario partir de la propia experiencia vital y de la revaloración de sus propios cuerpos, empezaron por reencontrarse con las fuerzas ancestrales de la historia negada, con la energía de la Naturaleza o Madre Tierra, se alimentaron de diversas corrientes ajenas a la universidad de aquel entonces, empezaron por recuperar y visibilizar historias otras, saberes otros, saberes no académicos; miraron $y$ experimentaron los problemas sociales y humanos desde la trasdisciplinariedad y la complejidad de lo real, se inmiscuyeron y nutrieron de la historia, la filosofía, la poesía, el cine, el arte, la música, el cosmos, el psicoanálisis, la economía política. Consideraron el conocimiento como un proceso intersubjetivo en un campo de fuerzas, teñido de color, de diferencia sexual y de control del trabajo público y privado.

Las reglas epistémicas positivistas y neopositivistas racializadas patriarcales que establecen la verdad o falsedad absoluta del conocimiento empezaron a ser cuestionadas por los cuerpos y saberes subalternizados.

Contribuyeron a que la teoría de la colonialidad del poder ampliara su visión, pues se comprendió que las relaciones de dominación, de explotación y conflicto atraviesan el saber y la vida social a través de la clasificación no solo a partir de la idea de raza, del eurocentrismo y del patrón global de poder sino también de la diferencia sexual.

La educación imperante, a través del lenguaje, en sus múltiples expresiones, desplegado por las tecnologías de la información y la comunicación, por las instituciones educativas, entre ellas la universidad, los medios de comunicación, los videojuegos, la religión, las leyes, las normas, los agentes de socialización en general contribuyen a construir el cuerpo como realidad sexuada y depositaria de categorías de percepción y apreciación sexuante dentro de los patrones de la dominación masculina y patriarcal. Se encarna en el cuerpo con principios jerárquicos de la clasificación social dominante, constituye algo así como un programa de cómo debemos ver, actuar, amar... y reproducir el orden social. Por eso, muchas veces el sentir emancipatorio de los procesos de descolonialidad es traicionado por el lenguaje del cuerpo.

Como lo he mencionado en otra ocasión, la dificultad de la gesta de formas de autogobierno, el esperar que haya siempre un padre, una madre, un guía, un maestro, un estratega, un jefe de partido, un teórico, en suma un salvador que ordene y tutele la existencia social, nuestras vidas y el saber, entre otros factores, también es una expresión de la dominación y educación patriarcal. Por eso, necesitamos fortalecer las autonomías individuales y colectivas, lo cual no supone negar la "autoridad", sino más bien entenderla como alguien que acompaña en relaciones desconcentradas/socializadas de poder que permita la formación autónoma e interdependencia saludable de las gentes y colectivos.

\section{La perspectiva de género, la interculturalidad descolonial y la estructura curricular}

La mirada sociohistórica en los cursos de teoría social con un enfoque de género e intercultural descolonial se torna ineludible. Nuestra crítica a la tradición patriarcal en el conocimiento radica en que continua reproduciendo el dominio del sexismo androcéntrico y la racialidad en las ciencias sociales, que se expresa al invisivilizar los conocimientos producidos por las mujeres y los pueblos «no blancos» en las asignaturas y la investigación

En el curso de teoría sociológica, por ejemplo, en el caso sanmarquino, se suele reflexionar sólo en torno a los clásicos europeos: Marx, Weber, Durkheim, Latour, 
Bourdieu, Bauman, por mencionar a algunos; es tiempo de visivilizar las reflexiones y propuestas de clásicos como Felipe Guamán Poma, Flora Tristán, Marianne Weber, Rosa Luxemburgo, Mercedes Cabello, Hannah Arendt, Carole Pateman, Ochi Curiel, Silvia Marcos, Rita Segato, entre muchas y muchos más. El propósito de está apertura al «no saber» no es estrictamente apelar al reconocimiento histórico sino establecer una perspectiva dialógica con los puntos de vista y epistemes que fueron subalternizados y que constituyen alternativas frente a la crisis que atraviesa el planeta y que por lo mismo permite una mejor aproximación y comprensión de lo real.

Flora Tristán y Marx coexistieron en el mismo espacio y tiempo, pero la teoría social solo da cuenta del segundo. Tristán, de formación autodidacta, reflexiona sobre las condiciones de vida de los obreros y las obreras, sostiene que ellos y ellas construyen la historia y que urge su organización de manera autónoma ante el mercado y el estado, es decir propone la organización independiente de lo que hoy se denomina «sociedad civil». Ante el trabajo esclavizante, agotador y alienante, exacerbada por el capitalismo, su propuesta se inspira en el carácter creativo, entorno al sentido arte-sanal de la tradición del compagnonnage, reivindica el trabajo manual, propone no disociarlo del trabajo intelectual, adelantándose de esta manera a Badiou (2012), cuestiona que la categoría humanidad aluda simplemente al hombre, que la mujer haya devenido en la proletaria del proletario, exige que los derechos conquistados por la Revolución Francesa se extienda a las mujeres y hombres trabajadores. Si lo único que tienen de propiedad los obreros son sus brazos, «para que la clase obrera pueda gozar con seguridad y garantías de su propiedad (como dice el artículo ocho), se le tiene que reconocer en principio ( y también en la realidad) el libre disfrute y garantía de su propiedad", afirma. (Tristán, 2011: 41) El sentido de propiedad alude a disponer con goce de la propia energía corporal que brota de las manos, nervios, músculos, intelecto etc., convertir el cuerpo - sentido como ajeno- en propio. Se cuestiona el poder sobre el cuerpo de las trabajadoras y los trabajadores. Podría problematizarse, esta afirmación, desde diversos ángulos, bien a partir de la victoria de la idea de "propiedad» o mas bien la posibilidad de recuperar el yo biosocial integral en tanto cuerpo, psique, cosmos, debido a que el libre disfrute supone la puesta en cuestión de la acumulación sin fin.
Felipe Guamán Poma de Ayala realiza el primer diagnóstico socioeconómico de la sociedad colonial en el siglo Xvi desde la afirmación indígena que no niega aprender de Occidenteen constante tensión descolonial; es el primer etnógrafo, historiador, sociólogo que se autoidentifica como cronista, indio ladino, señor y príncipe; que propone la necesidad imperante de «mudar la vida», porque sintió su insostenibilidad en la condición y relación colonial, comprendió que los seres humanos son los que hacen la historia y no las divinidades $\mathrm{y}$, al mismo tiempo, propuso alternativas basadas en la educación y «Bien Vivir». Antecedió al surgimiento de la idea de cambio en Europa precisado por Locke. La metodología de Guamán Poma se basó en saber escuchar, en el conocimiento y comprensión de la complejidad del territorio, de la diversidad de las lenguas y prácticas socioculturales existentes en cada región (Ortiz, 2010). ¿Cómo ignorar su propuesta? La visión transformativa se ha ido perdiendo en las ciencias sociales ¿Cómo no tener presente el principio de «mudar la vida» para el «bien vivir» de todas y todos?

Pensar la universidad y, en particular, la Facultad de Ciencias Sociales, implica sentipensarla desde el conocimiento fronterizo, desde el pensamiento del afuera diría Foucault, supone pensar y actuar desde fuera del orden disciplinario tan dependiente del eurocentrismo, del orden socio simbólico patriarcal, pero también desde dentro, agrego, desde los propios recodos del poder, supone pensarla desde la experiencia histórica de los dominados, mediante dimensiones múltiples que se interdefinen y condicionan por la heterogeneidad estructural, territorial y cultural del país, que se expresa también en la composición de la población estudiantil y de los docentes.

Una experiencia interesante, aunque suspendida por acción del gobierno de Correa en Ecuador, pero continuada de manera no oficial por los Yachay/ Amauta, es la propuesta educativa de la Universidad Intercultural de las Nacionalidades y los Pueblos indígenas Amawtay Wasi que «se organizó en cuatro centros curriculares: Ushay-Yachay o de la interculturalidad, Ruray-Ushay o de las Tecnociencias para la vida; Munay-Ruray o del Mundo vivo; y Yachay-Munay o de las Cosmovisiones. El centro de los cuatro centros es Kawsay, 'Vida' o también 'conocimiento'. Se entiende así el significado de Sumak Kawsay, que malamente se traduce como 'Buen vivir'. Sumak Kausay sería la plenitud del vivir a través del conocimiento. Este es un modelo de 
pedagogía decolonial y por lo tanto de universidad decolonial» (Mignolo, 2014)

En el caso sanmarquino, en cada una de las escuelas de la facultad existen esfuerzos individuales, mas es imprescindible colectivizar esos esfuerzos, entendiendo que el conocimiento es una construcción dialógica, por lo tanto colectiva.

\section{Conclusiones prelimirares}

Nuestra historia en relación al conocimiento no comienza con la creación de las universidades. Las civilizaciones del antiguo Perú, tuvieron patrones propios de formación e investigación.

La universidad desde su fundación contribuyó al proceso de colonización y despojo mediante las especialidades y materias diseñadas para ello. En el episteme impuesto, la ciencia, se asoció a Occidente y a la racionalidad instrumentalizada de los hombres propietarios «blancos», jefes de familia. Todo saber producido por la civilización inca y pre inca, fue considerado creencia irrelevante de pueblos primitivos y sexos débiles no viriles en estado de naturaleza.

El objetivo de la ciencia desde la razón colonial radicó en perfeccionar el conocimiento de la naturaleza para su mejor explotación. Durkheim, Niesztche y Wallerstein nos recuerdan que la ciencia se fue alejando de valores como la generosidad, la belleza, el amor.

Las universidades sudamericanas siguieron $\mathrm{y}$ afianzaron la mirada lineal y eurocéntrica, y junto a la iglesia potenciaron la dominación y organización sociosimbólico patriarcal, la explotación de la naturaleza, la racialización de las relaciones sociales que se enraizó en todas las instituciones.

El episteme/ cosmovisión hegemónico impuesto mediante la fragmentación disciplinaria en ciencias sociales y humanidades, y las relaciones de dominación indicadas impiden acercarnos en mejores condiciones al entendimiento de la complejidad de lo real, a las relaciones materiales y a la dimensión simbólica que lo componen.

La nueva Ley universitaria 30220 supone solo la modernización de la universidad. La crisis generalizada hace indispensable mutar la vida en general y la vida universitaria en particular, propiciando una educación pública pluralista, pluriversal en términos de Boaventura de Sousa, multiversidad en términos de Edgar Morin vinculada a la problemática del mundo social y la gratuidad de la enseńanza, recuperando su carácter de bien público con una comunidad universitaria plural, intercultural, democrática y descolonial orientada a las necesidades de los pueblos.

Con todo, existen numerosos esfuerzos por establecer nuevas perspectivas desde visiones dialógicas, de género e interculturales descoloniales. Esto supone el desprendimiento o ruptura epistémica del marco de saber y poder que se impuso e impone con los procesos coloniales y la colonialidad del saber en el mundo de los afectos, el trabajo y el territorio.

Pensar la pluriversidad como una comunidad en la que coexisten los saberes académicos y los no académicos, escuchando, conociendo y comprendiendo epistemes/cosmovisiones de distinto origen unidos en el debate mediante una profunda solidaridad en torno al amor y disciplina del saber (Dussel, 2013) sobre las situaciones locales, del Perú y el mundo y como institución pública que presta servicios por el bienestar de las comunidades subalternizadas y no por intereses mezquinos de los gobiernos y corporaciones. Para esto, es inexcusable volver a los orígenes considerando a la Pachamama/cosmos como fuente de vida y no como un objeto del que hay que extraer indiscriminadamente «recursos naturales». Por lo que premia recuperar el carácter sagrado de la vida.

Marzo, 2017

\section{Bibliografía}

Arguedas, JM. (1978). «No soy un aculturado», en Tarea, boletín de educación popular, Lima, No 26-27, Juliooctubre 1978, p. 2.

Badiou, A. (2012). «El militante fiel», entrevista de Verónica Gago, en la Sala del Tesoro Público de la Biblioteca Nacional, 9 de Mayo, Buenos Aires.

http://anarquiacoronada.blogspot.pe/2013/05/parapasar-el-finde-el-militante-fiel.html

Cabello de Carbonera, M. (2001). El conspirador. Autobiografia de un hombre público. Lima: Kavia Cobaya Editores.

Cornejo, M. (1910). Sociología general, Madrid, Imprenta de los Hijos de M. G. Hernández, 1908-1910.

De Sousa Santos, B. (2005). La universidad en el siglo XXI. Para una reforma democrática y emancipadora de la universidad. Buenos Aires: Libros del LPP.

De Sousa Santos, B. (2006). Conocer desde el Sur. Para una cultura politica emancipatoria. Lima: Fondo Editorial de la Facultad de Ciencias Sociales de la UNMSM. 
Dussel, E. (2013). «Discurso de presentación del Dr. Enrique Dussel ante la comunidad de la UACM», https:// filosofiauacm.wordpress.com/2013/03/11/discurso-deldr-enrique-dussel-como-rector-interino-de-la-uacm/ //www.youtube.com/watch?v=6Udk1wH-hQw

Dussel, E. (2001). «Eurocentrismo y modernidad (Introducción a las lecturas de Frankfurt)», Capitalismo y geopolitica del conocimiento: el eurocentrismo y la filosofía de la liberación en el debate intelectual contemporáneo. Mignolo (comp). Buenos Aires: Ed. El Signo.

Foucault, M. (2014). Las palabras y las cosas. México: Siglo XXI [1968].

Freire, P. (2011). Pedagogía de la esperanza. México: Siglo XXI

GermanÁ, C. (2014). Conferencia sobre la Universidad. Lima: Universidad Ricardo Palma.

Guaman Poma de Ayala, F. (1993) Nueva corónica y buen gobierno». Lima: FCE.

LANDER, E. (2015). «Venezuela: La universidad tradicional y la universidad bolivariana», (conferencia). Quito, Universidad Andina Simón Bolívar - Sede Ecuador. Video publicado el 8 de julio de 2015: https://www.youtube.com/watch? $\mathrm{v}=\mathrm{eVeS} 2 \mathrm{JfnKqs}$

Mariátegui, J. C. (1995). 7 ensayos de interpretación de la realidad peruana. Lima: Amauta [1928].

Mignolo, W. (2014). «El control del cuerpo y los saberes», en http://www.pagina12.com.ar/diario/universidad/10250276-2014-07-08.html

Mignolo, W. (2012). «El pensamiento des-colonial, desprendimiento y apertura: un manifiesto", Indymedia, 11.02.2012 http://argentina.indymedia.org/ news/2012/02/808332.php

Morin, E. (1999). Los siete saberes necesarios para la educación del futuro. UNESCO.

Ortiz Fernández, C. (2014). Poéticas afroindoamericanas. Episteme, cuerpo y territorio. Lima: Pakarina Ediciones/ Facultad de Letras de la UNMSM.

Ortiz Fernández, C. (2011). "Género, colonialidad del poder, conocimiento y las políticas de igualdad hoy. Seducción, género y poder en Dioses y hombres de Huarochirí y la Nueva corónica y buen gobierno", en Revista de Sociología, Fac. de CC. SS. de la UNMSM, Lima, No 21, pp. 185-201.

Ortiz Fernández, C. (2004). Proceso de descolonización del imaginario y del conocimiento en América Latina. Poéticas de la violencia de la crisis. Lima: Universidad Nacional Mayor de San Marcos.
Ortiz Fernández, C. (2008). «Mujeres, Universidad y Sociedad», en Revista de Sociología, (Lima): 18-19, pp. $147-165$

Ortiz Fernández, C. (1993). "Clorinda Matto de Turner. La censura y la fe. Modernidad, etnicidad y género", tesis para optar la licenciatura en Sociología. Facultad de Ciencias Sociales de la UNMSM.

Quijano, A. (2007). «Don Quijote y los molinos de viento en América Latina», en: Investigaciones Sociales, Año X, No. 16. Lima: UNMSM /Instituto de Investigaciones Histórico Sociales, pp. 347-368.

Quijano, A. (2010). «'Bien vivir’ para redistribuir el poder. Los pueblos indígenas y su propuesta alternativa en tiempos de dominación global», en: Oxfam, Pobreza, desigualdad y desarrollo en el Perú. Informe anual 2009-2010.

Quijano, A. (2000). «Colonialidad del poder, eurocentrismo y América Latina», Edgardo Lander (comp.), Colonialidad del saber: eurocentrismo y ciencias sociales. Perspectivas latinoamericanas. Buenos Aires: CLACSO, pp. 201-246.

Quijano, A. (1991). "Colonialidad y modernidad/ racionalidad», en Revista del Instituto Indigenista Peruano, Vol. 13, No. 29, Lima, pp. 11-20.

Quijano, A. (1988). Modernidad, identidad y utopia en América Latina. Lima: Sociedad y política.

Rivera Cusicanqui, S. (2006). «El potencial epistemológico y teórico de la historia oral: de la lógica instrumental a la descolonización del historia», en Seminario sociología de la imagen. Una visión desde la historia andina. Lima: PDTG/ UNMSM.

Sepúlveda, J. de (1996). Tratado sobre las justas causas de la guerra contra los indios. México: FCE [1550].

Vandana, S.; Mies, M. (1997). Ecofeminismo, teoría crítica y perspectivas. Barcelona: Icaria [1993].

Snow, Ch. (1988). Las dos culturas. Buenos Aires: Nueva Visión.

TRISTAN, F. (2011). La unión obrera. Lima: UNMSM.

Wallerstein, I. (1997). Abrir las ciencias sociales. México: Siglo XXI.

WALSH, C. (2015). «Universidad, seres, saberes y (geo) poder(es) en Ecuador y América del Sur», (conferencia). Quito, Universidad Andina Simón Bolívar - Sede Ecuador. Video publicado el 24 de junio del 2015: https://www.youtube.com/watch?v=a-boM_qMr50 